\title{
Aneurisma em ponte de veia safena para artéria coronária marginal esquerda, roto para o brônquio esquerdo
}

\author{
Luiz César Guarita SOUZA* ${ }^{*}$ Salomon O. ROJAS ${ }^{*}$, Ricardo MAZZIERI ${ }^{*}$, Dante F. SENRA*, \\ Marcos F. BERLINCK*, Januário Manoel de SOUZA*, Sérgio Almeida de OLIVEIRA*
}

Souza L C G, Rojas S O, Mazzieri R, Senra D F, Berlinck M F, Souza J M, Oliveira S A - Aneurisma em ponte de veia safena para artéria coronária marginal esquerda, roto para o brônquio esquerdo: Rev Bras Cir Cardiovasc 1996; 11 (4): 311-3.

RESUMO: Paciente com duas cirurgias prévias de revascularização do miocárdio há 20 e 10 anos, respectivamente, apresentou subitamente quadro de dispnéia, dor torácica e hemoptise. Aos exames complementares, foi observado um grande aneurisma da ponte de veia safena para artéria marginal esquerda, parcialmente roto em brônquio esquerdo. O aneurisma foi corrigido, com sucesso, mas o paciente veio a falecer no $15^{\circ}$ pós-operatório em conseqũência de uma infecçāo pulmonar.

DESCRITORES: Aneurisma, cirurgia. Aneurisma roto, cirurgia. Veia safena, cirurgia. Ponte de veia safena. Artéria coronária, cirurgia. Ponte para artéria coronária.

\section{RELATO DO CASO}

J.G.M., 68 anos, branco, tabagista e diabético de longa data, foi submetido a cirurgia de revascularização do miocárdio com ponte de veia safena para a artéria interventricular anterior em 1975. Após 10 anos, foi reoperado com realização de pontes de veia safena para a artéria coronária direita e para a artéria marginal esquerda, sendo esta última com trajeto retro-aórtico passando pelo seio transverso. A ponte para a artéria interventricular anterior estava ocluída, sendo realizada endarterectomia e anastomose com a artéria torácica interna esquerda.

Teve alta hospitalar em bom estado geral, permanecendo assintomático até dezembro de 1995 , quando, subitamente, apresentou dispnéia, dor torá- cica e hemoptise, sendo internado para investigação, após 15 dias do ínicio dos síntomas. Ao exame físico, estava descorado, dispnéico, com episódios freqüentes de tosse com escarros hemoptóicos. A pressão arterial era de $140 / 90 \mathrm{mmHg}$, freqüência cardíaca com ritmo irregular de 69 batimentos cardíacos por minuto. $O$ eletrocardiograma mostrou rítmo de fibrilação atrial, com distúrbio de condução do ramo direito e isquemia ínfero-lateral. A radiografia de tórax mostrava congestão pulmonar moderada e difusa. A tomografia computadorizada revelou lesão expansiva mediastinal, localizada à esquerda do átrio esquerdo, deslocando a veia pulmonar inferior esquerda posteriormente. A lesão estava em intima relação com a artéria pulmonar esquerda e com o brônquio do lobo inferior esquer-

Trabalho realizado no Serviço de Cirurgia Cardiovascular do Prof. Dr. Sérgio Almeida de Oliveira, no Hospital Beneficência Portuguesa de São Paulo. São Paulo, SP, Brasil.

Recebido para publicação em outubro de 1996.

* Do Serviço de Cirurgia Cardiovascular do Prof. Dr. Sérgio Almeida de Oliveira - Hospital da Beneficência Portuguesa de São Paulo.

Endereço para correspondência: Luiz César Guarita Souza. Rua Maestro Cardim, 769 - $2^{2}$ Andar - Sala 233. São Paulo, SP, Brasil. 
Souza L C G, Rojas S O, Mazzieri R, Senra D F, Berlinck M F, Souza J M, Oliveira S A - Aneurisma em ponte de veia safena para artéria coronária marginal esquerda, roto para o brônquio esquerdo: $\quad$ Rev Bras Cir Cardiovasc 1996;11 (4):311-3 .

do, tendo densidade semelhante ao das partes moles, sugerindo que a lesão fosse de natureza vascular (Figura 1).

À angiografia pulmonar observou-se circulação arterial pulmonar com aspecto angiográfico dentro dos limites da normalidade, não havendo evidência de aneurisma ao nível das artérias pulmonares. Identificou-se, no entanto, deslocamento cranial da veia do lobo inferior à esquerda, possivelmente devido ao efeito expansivo da lesão evidenciada à tomografia. O tempo de circulação arteriovenosa transcorreu normalmente, não havendo evidência de drenagem venosa precoce. Observou-se, também, imagem sugestiva de contraste residual em brônquio esquerdo, possivelmente devido à cineangiocoronariografia, suspeitando-se, desta forma, de uma fístula coronário-brônquica (Figura 2).

A cineangiocoronariografia mostrou oclusão proximal da artéria coronária direita, oclusão proximal da artéria interventricular anterior e oclusão do ramo marginal esquerdo da artéria circunflexa. As pontes das veias safenas para artérias coronárias direita $e$ marginal esquerda estavam pérvias. Entretanto, a ponte de veia safena para a artéria marginal esquerda apresentava, em seu terço distal, um grande aneurisma (Figura 3).

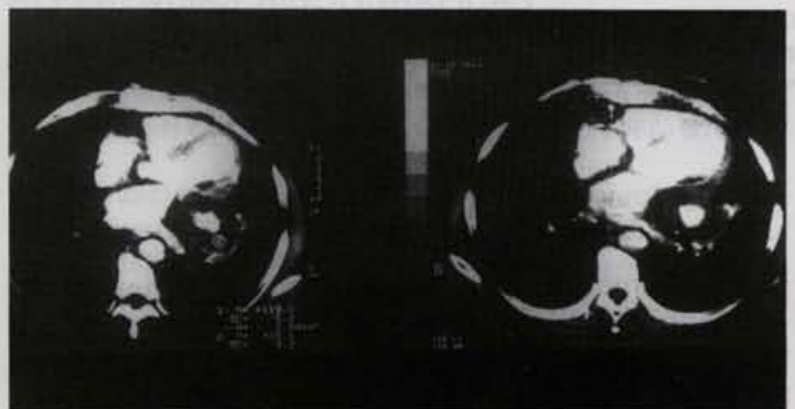

Fig. 1 - Lesão expansiva mediastinal, tendo densidade semelhante ao das partes moles, sugerindo que a lesāo fosse de natureza vascular.

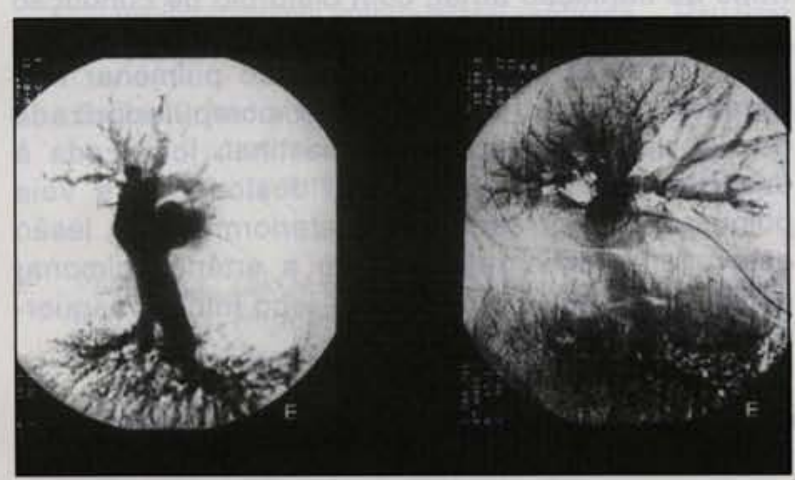

Fig. 2 - Deslocamento cranial da veia do lobo inferior à esquerda, possivelmente devido ao efeito expansivo da lesão evidenciada à tomografia.

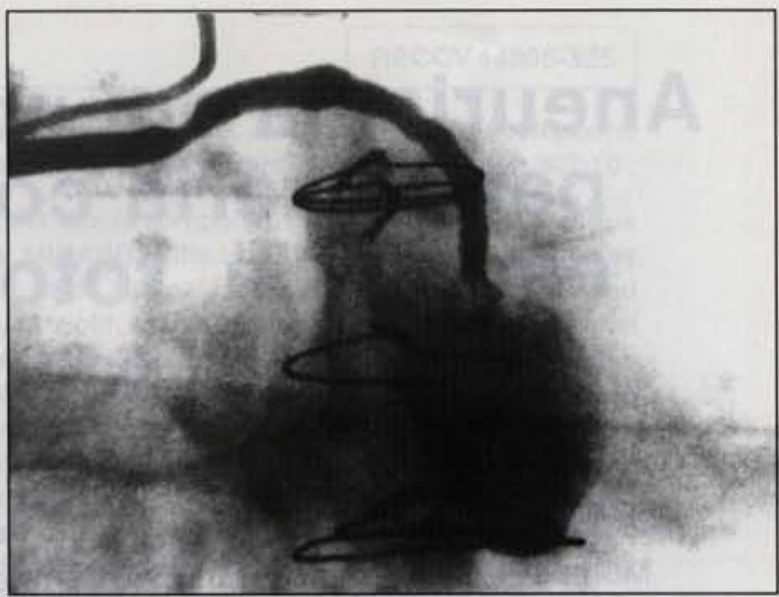

Fig. 3 - Ponte de veia safena para a artéria marginal esquerda apresentava, em seu terço distal, um grande aneurisma.

*

A artéria torácica interna estava anastomosada, a artéria interventricular anterior com bom fluxo e sem lesões. A ventriculografia esquerda evidenciou hipocinesia ântero-lateral.

Com o diagnóstico de grande aneurisma da ponte de veia safena para a artéria marginal esquerda, parcialmente roto para o brônquio esquerdo, foi indicada a correção cirúrgica. A operação foi realizada através de uma esternotomia mediana anterior. A circulação extracorpórea foi iniciada com canulação de artéria e veias femorais esquerdas. Após liberar o coração das aderências, o átrio direito foi canulado para completar a drenagem venosa. A temperatura sistêmica foi baixada para $30^{\circ} \mathrm{C}$. A aorta ascendente foi pinçada, sendo realizada cardioplegia anterógrada sangüínea oxigenada. A ponte para a artéria marginal esquerda foi isolada no seu trajeto retroaórtico e ligada. Após exposição da face lateral do ventrículo esquerdo, o aneurisma da ponte foi melhor visibilizado; localizava-se logo antes da anastomose com a artéria coronária marginal esquerda, medindo aproximadamente $4,0 \mathrm{~cm}$ $x 5,0 \mathrm{~cm}$. O aneurisma foi incisado, havia trombos, os quais foram removidos.

O pericárdio posterior estava rompido pelo aneurisma, o qual invadia o lobo pulmonar inferior esquerdo. Havia contigüidade do aneurisma com o brônquio esquerdo. A veia safena foi ligada antes e após o aneurisma. O paciente foi reaquecido e a circulação extracorpórea interrompida. O paciente manteve-se em boas condições hemodinâmicas. 0 mediastino foi drenado e realizada síntese da toracotomia.

A evolução pós-operatória inicial foi satisfatória, sendo o paciente extubado algumas horas após a operação. Nos primeiros quatro dias, manteve-se bem, embora com muita secreção pulmonar e fre- 
Souza L C G, Rojas S O, Mazzieri R, Senra D F, Berlinck M F, Souza J M, Oliveira S A - Aneurisma em ponte de veia safena para artéria coronária marginal esquerda, roto para o brônquio esquerdo: $\quad$ Rev Bras Cir Cardiovasc 1996; 11 (4):311-3.

qüentes broncoespasmos, controlados com fisioterapia respiratória e uso de broncodilatador e antibioticoterapia. No $5^{2}$ pós-operatório, foi diagnosticada infecção pulmonar, necessitando nova entubação manual e assistência ventilatória mecânica. A insuficiência respiratória foi progressiva, levando a parada cárdio-respiratória no $15^{\circ}$ pós-operatório, evoluindo ao óbito.

\section{COMENTÁRIOS}

O comprometimento dos enxertos de veia safena pela aterosclerose é freqüente após alguns anos de funcionamento, sendo mais acentuado nos pacientes com graves dislipidemias. Esta é a causa comum da oclusão tardia das pontes de veia safena. Dilataçōes aneurismáticas das veias, secundárias a aterosclerose têm sido observadas não raramente; entretanto, o caso aqui relatado reveste-se de algumas peculiaridades, como o grande volume da formação aneurismática e a complicação com fistulização para o pulmão, levando ao aparecimento de hemoptise.
Embora não tenha sido comprovada a presença de comunicação direta do aneurisma com a árvore brônquica, a hemorragia poderia ter sido provocada por pequenas roturas tamponadas ou apenas por escara de decúbito sobre a árvore brônquica.

Dilatações aneurismáticas das veias safenas com acentuada degeneração aterosclerótica são comuns, embora não maior que uma ou duas vezes - diâmetro original da veia. Estas dilataçōes levam à oclusão do enxerto por trombose, sendo excepcional a evolução para rotura.

A correção cirúrgica pôde ser realizada com ligadura da veia safena (ponte) antes e após o aneurisma. Infelizmente, o quadro de insuficiência respiratória agravou-se no pós-operatório, levando o paciente ao óbito.

A prevenção da aterosclerose com adequado regime dietético e medicamentoso deve sempre ser observado nos pacientes operados com pontes de veia safena para maior sobrevida dos enxertos e evitarem-se complicações, como a aqui descrita.

RBCCV 44205-326

Souza L C G, Rojas S O, Mazzieri R, Senra D F, Berlinck M F, Souza J M, Oliveira S A - Aneurysm in the saphenous vein bypass graft to the left marginal coronary artery, broked up to the left bronchus. Rev Bras Cir Cardiovasc 1996; 11 (4): 311-3.

ABSTRACT: A patient who suffered two previous myocardium revascularization surgeries, ten and twenty years ago, respectively, showed a history of dyspnea, chest pain and hemoptysis suddenly. In the folllowing examinations, a big saphenous vein bypass graft aneurysm was observed to the left marginal artery, partially broked up in the left bronchus. The aneurysm was corrected sucessfully, but the patient died 15 days after the surgery due to a pulmonary infection.

DESCRIPTORS: Aneurysm, surgery. Ruptured aneurysm, surgery. Saphenous vein, surgery. Saphenous vein bypass. Coronary artery surgery. Coronary artery bypass. 